\title{
Design of a prototype press for in-field pressing of sweet sorghum and sweet pearl millet biomass
}

\author{
Lefebvre, Nicholas ${ }^{1}$, Khelifi, Mohamed ${ }^{2, *}$, De Ladurantaye, Yannick ${ }^{3}$ \\ 1,2, 3 Université Laval, Quebec, Canada
}

\author{
Index Terms \\ Sweet sorghum \\ sweet pearl millet \\ prototype press \\ juice extraction
}

Received: 19 October 2014

Accepted: 20 July 2015

Published: 15 October 2015

\begin{abstract}
With the growing demand for biofuels, ethanol production is rising. Alternative energy crops have been investigated to get better yield from little resources. Sweet sorghum and sweet pearl millet are promising energy crops. However, the sugar is mainly located in the juice rather than in the grain. Usually, the biomass of these crops is carried to a plant where it is handled like that of sugarcane. With the rise of the transportation fees, carrying the biomass leaves less profit to the producer and causes the loss of organic matter or forage. The objective of the research study was to design, build, and test an infield mobile juice extraction prototype press. This allows pressing on-the-run the biomass harvested with a forage harvester. The pressed material (bagasse) is dumped on the ground while the juice is collected. The prototype press was built in the summer of 2014 and preliminary tests were carried out in the field. Obtained results are promising as 57\% of the total water was extracted. More tests will be carried out to optimize the prototype press.
\end{abstract}

(C) 2015 The Author(s). Published by TAF Publishing.

hectare of these two crops is expected to be up to $72 \%$ more than that of corn.

Currently, there is no juice extracting machine commercially available to do this operation on the farm. Current processes imply carrying the whole plant to a transformation plant. Once in the plant, the juice is extracted using industrial roll presses specifically designed for sugar cane. At the end of the process, the bagasse is discarded, either burned or buried. Carrying the whole plant results in additional costs for transportation and organic matter deterioration of forage intended for animals.

The objective of the study was to design and test a juice extraction prototype press that can be easily operated in the field.

\section{LITERATURE REVIEW}

\section{A. Team's Previous Work}

In order to explore the best way of extracting the juice

\footnotetext{
* Corresponding author: Lefebvre, Nicholas

E-mail: nicholas.lefebvre.1@ulaval.ca
} 
from sweet sorghum and sweet pearl millet biomass,[1] carried out many tests in the summers of 2009, 2010, and 2012. Tests in the first two years were conducted using Vincent Corp. screw presses (models CP-4 and CP-6). Obtained results were satisfactory in terms of extraction rates but a high concentration of suspended solids was noticed in the extracted juice which could be unsuitable for ethanol production. Other juice extraction tests were conducted with a vertical hydraulic compression chamber press built at the Department of Soils and Agri-Food Engineering of Université Laval, Quebec, Canada. The use of this compression chamber resulted in good extraction rates and a sediments-free juice. The extraction and operation times are however prohibitive for further use.

Other tests were conducted during the summer of 2012 using two presses designed and built at the Department of Soils and Agri-Food Engineering of Université Laval, Quebec, Canada. The first was a roller press mainly consisting off our horizontal rollers, each $270 \mathrm{~mm}$ (10.625 in.) in diameter and $304.8 \mathrm{~mm}$ (12 in.) long, placed in a way to allow three pressings per run [2]. Although sweet sorghum and sweet pearl millet canes seemed well pressed, a high redeposit rate resulted in a very low quantity of extracted juice. It was therefore concluded that the roller press is not suitable for extracting the juice from sweet pearl millet biomass, given that very low extraction yield was obtained for this crop species. The second press was a horizontal piston press consisting of a 0.048 mcompression chamber and a 101.6-mm (4") hydraulic piston. The use of this press yielded juice extraction rates varying from 35 to $42 \%$ and very little suspended solids.

\section{B. Previous Extraction Systems}

So far, some researchers/companies have patented field extraction systems but with little commercial success. For example, McClune industries patented a whole sweet sorghum in-farm processing system [3]. This system covers all the aspects starting from harvesting to the sale on the market, passing through the extraction and fermentation. The patent includes a press designed to extract the juice in field. However, the capacity of the press is only one acre/hour, which is slow for a commercial operation. The press harvests the whole plant with a single row cornhead and extracts the juice with a series of pairs of rollers.

[4]developed a three-roller-belt extractor of juice from sweet sorghum. They showed that the extraction ratio could be increased if the biomass was compressed twice. For this purpose, they built a five-roller-belt extractor prototype and obtained a better extraction ratio in particular when the biomass was chopped to about $17 \mathrm{~mm}$ long and when the four gaps between the five rollers were 7, 4, 2, and $2 \mathrm{~mm}$, respectively. [4]also showed that the juice extraction ratio decreased with increasing roller speed.

Recently, [5] designed and tested a three-pair roller press. They tested two types of rollers: smooth and grooved as well as a combination of these two. Obtained results indicated that the best extraction efficiency (45\%) was achieved when the first two pairs of rollers were grooved. The use of smooth or grooved rollers was comparable in terms of juice extraction.

\section{MATERIALS AND METHODS}

\section{Design of the Press}

The design of the press was made through CAD and FEA using SolidWorks [6]. All sheetmetal components were laser cut whereas the remaining components are standard profiles commercially available. The theory of Mechanics of Materials [7] was applied to make all the necessary computation while the validation was carried out through FEA for further optimization.

\section{Assembly of the Press}

The prototype press was built in the multi-services shop of the Department of Soils and Agri-Food Engineering of Université Laval. A MIG welder, a chain block, and various power tools were used to complete the assembly. The assembly was divided into 12 separate sub-assemblies.

\section{E. Biomass}

Plots of sweet sorghum were seeded at the Université Laval experimental station in Saint-Augustin-deDesmaures, Quebec, Canada. The plots were harvested on September 19, 2015 using a Dion 1224 (Model F-41) forage harvester from the company Dion Machinerie, Quebec, Canada equipped with a non-directional head (Model Dion F-61).

\section{F.Field Tests}

Chopped biomass was placed into 100 L containers, weighed and then poured in the first compression chamber of the press. Thereafter, the pressure was applied on the biomass for two minutes. Then, the block of biomass was transferred to the high pressure chamber and pressed again until the juice flow nearly stopped. Finally, the block of bagasse was dumped out. The juice was collected at the bottom of the press and weighed. Three 1kg biomass samples were taken before and after each pressing for eventual water content analysis.

\section{G. Water Content Analysis}


The samples of biomass were dried at $95^{\circ} \mathrm{C}$ for 72 hours or until mass loss stopped. They were then weighed again to measure the moisture content and compute the ratio of water extracted as described in [8].

The theoretical moisture content (MC) of the bagasse was determined from the following equation:

ThreoreticalMC $=\frac{(\text { Watercontent })-(\text { Extracted juice })}{(\text { Drymatter })}(1)$

Juice losses were calculated as:

$$
=(\text { Theoretical MC }- \text { Measured MC) } * \text { Dry matter }
$$

Water extraction rate was computed as: Water extraction rate

$$
=\frac{(\text { Extracted juice })+(\text { Losses })}{\text { Water content }}
$$

\section{RESULTS AND DISCUSSION}

A commercial prototype press mounted on a wheeled frame was successfully designed (Figure 1). This press can be used in the field along with a harvester to extract the juice from the harvested biomass. Optimized sheet metal construction kept the weight down to $7250 \mathrm{~kg}$. All press parts were optimized for a $2000 \mathrm{~h}$ life expectancy. The assembly was made fast with positioning features, standardized parts and integrated components. It was kept within road legal limits of dimensions and weight.

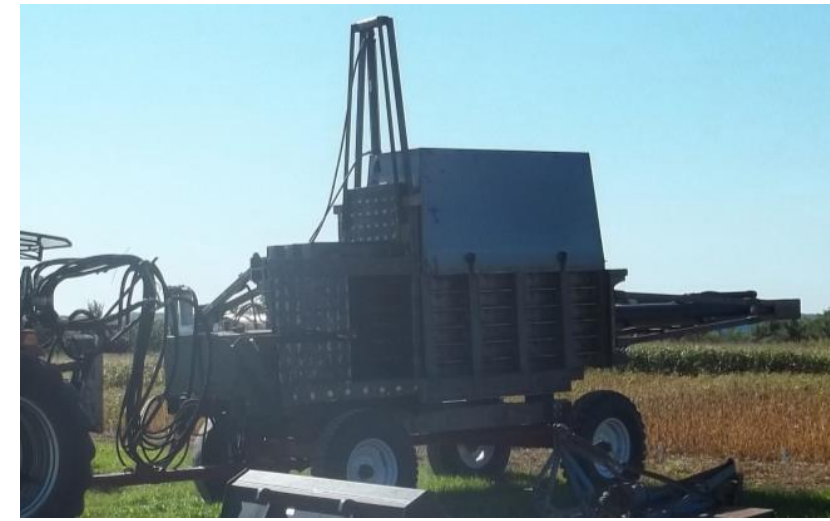

Fig. 1. Fully assembled press.

The mechanical behavior of the press met our expectation except for the friction forces of the doors, which were underestimated. Indeed, the pressed biomass applied a backpressure on the doors greater than that expected, which prevented them from moving. This was solved by slightly adjusting the operating pressure.

Also, major leaks appeared during the tests. The juice was flowing away from punched holes in the cylinder or from the doorsills. Component sealing will be explored since the pressure was applied gradually to prevent losses, which considerably slowed the pressing process. Losses were determined by computing the difference between the rate of extracted juice in the field and that of the moisture content of the dried samples. They varied from 6.5 to $14.3 \%$.

Water content analyses showed that the moisture of the pressed biomass, which was initially $83 \%(17 \%$ dry matter), went down to $70 \%$ on a wet basis. Overall, a water extraction rate as high as $57 \%$ was obtained and mean of $45 \%$ of the total mass was extracted (Table 1 ).

TABLE 1

RESULTS OF THE TESTS CARRIED OUT USING THE COMMERCIAL PROTOTYPE PRESS

\begin{tabular}{lccc}
\hline \hline Extraction & Extraction 1 & Extraction 2 & Extraction 3 \\
\hline Initial biomass (kg) & 627 & 717 & 699 \\
Dry matter of the initial biomass (kg) & 108 & 117 & 116 \\
Water content of the initial biomass (kg) & 519 & 599 & 582 \\
Extracted juice mass (kg) & 252 & 281 & 276 \\
Theoretical moisture content of the bagasse on a dry basis (\%) & 247 & 271 & 263 \\
Measured moisture content of the bagasse on a dry basis $(\%)$ & 208 & 254 & 226 \\
Losses (L) & 42 & 20 & 43 \\
$\%$ of mass extracted & 47 & 42 & 46 \\
\hline \hline
\end{tabular}




\section{CONCLUSION AND RECOMMENDATIONS}

Preliminary testing of the commercial prototype press showed that juice extraction on a large scale is feasible as interesting extraction rates were obtained. These rates are comparable to those obtained with a small-scale prototype used in a previous study []. Further improvements of the press should include automated sequences to get a better precision regarding the pressing times, especially if in field continuous pressing coupled with harvesting is expected. Also, data acquisition should be integrated into the prototype press to better understand the force/position curve, which allows better determining the caseloads and consequently optimizing the structure. Optimizing the components will result in reducing the production cost as well as the mass of the assembly. The force/position curve coupled with an eventual pressure/extraction curve would greatly help optimizing the pressing cycle, dimensioning the cylinders and the pump, and determining the cycle time.

\section{REFERENCES}

[1] H. S. Witsenhausen, "A class of hybrid-state continuous-time dynamic systems," IEEE Transactions on Automatic Control, vol. 11, no. 2, pp. 161-167, 1966.
[2] M. S. Branicky, V. S. Borkar and S. K. Mitter, "A unified framework for hybrid control: Model and optimal control theory," Automatic Control, IEEE Transactions on, vol. 43, no. 1, pp. 31-45, 1998.

[3] R. Alur, C. Courcoubetis, T. A. Henzinger and P. H. Ho, "Hybrid automata: An algorithmic approach to the specification and verification of hybrid systems, in Hybrid Systems," in Lecture notes in computer science, New York , Springer-Verlag, 1993.

[4] P. Antsaklis, "Special issue on hybrid systems: Theory and applications. A brief introduction to the theory and applications of hybrid systems," in Proc. of the IEEE, 2000.

[5] F. Torrisi and A. Bemporad, "HYSDEL-A tool for generating computational hybrid models for analysis and synthesis problems," IEEE Transactions on Control Systems Technology, vol. 12, no. 2, pp. 235-249., 2004.

[6] I. Kresno, "Perancangan perangkat MATLAB untuk ekuivalensi model sistem hybrid", dissertation, Bandung Inst. of Technology., Bandung, ID, 2005.

[7 ] H. Ye, A. N. Michel and L. Hou, "Stability theory for hybrid dynamical systems," IEEE Transactions on Automatic Control, vol. 43, no. 4, pp. 461-474,1998. 